\title{
IN-DEPTH SURVEY REPORT: \\ CONTROL OF PERCHLOROETHYLENE (PCE) \\ IN VAPOR DEGREASING OPERATIONS, SITE \#2
}

\author{
PRINCIPAL AUTHORS: \\ Daniel Almaguer \\ Stan Shulman \\ Amir Khan
}

REPORT DATE:

August, 2002

REPORT NO:

EPHB 256-16b

\author{
U.S. DEPARTMENT OF HEALTH AND HUMAN SERVICES \\ Public Health Service \\ Centers for Disease Control and Prevention \\ National Institute for Occupational Safety and Health \\ Division of Applied Research and Technology \\ Engineering and Physical Hazards Branch \\ 4676 Columbia Parkway, R5 \\ Cincinnati, Ohio 45226
}


SITES SURVEYED:

SIC CODE:

SURVEY DATES:

SURVEYS CONDUCTED BY:
Southeastern United States

3559

January 22-26, 2001

April 9-12, 2001

Daniel Almaguer, NIOSH

Amir Khan, NIOSH

Dan Farwick, NIOSH 


\section{DISCLAIMER}

Mention of company names or products does not constitute endorsement by the Centers for Disease Control and Prevention. 


\begin{abstract}
Worker exposures to perchloroethylene (PCE) occur in a large number of industries where PCE is used for organic solvent vapor cleaning (degreasing). Solvent degreasing does not constitute a distinct industrial category, but is an integral part of many major industries. This report examines worker exposures to PCE during the loading and unloading of parts, and the performance of an open-top vapor degreaser equipped with a local exhaust ventilation system at the loading/unloading station. Air samples for PCE were collected on two separate occasions covering five days of degreasing operations. The PCE concentrations measured in the building ranged from 21 to $38 \mathrm{ppm}$ during closed building conditions and ranged from $16.3 \mathrm{ppm}$ to 22.4 ppm during open building conditions. After repairs to the PCE vapor degreaser concentrations were further reduced to a range of $6.6 \mathrm{ppm}$ to $12.7 \mathrm{ppm}$ following the maintenance operations. A review of the sampling results showed that the degreaser operators were not exposed to perchloroethylene concentrations in excess of the OSHA PEL, but indicate that proper equipment maintenance effectively reduces employee exposure concentrations.
\end{abstract}




\section{BACKGROUND AND PURPOSE}

The National Institute for Occupational Safety and Health (NIOSH), working under an interagency agreement with the Office of Regulatory Analysis of the Occupational Safety and Health Administration (OSHA), is conducting a study to survey occupational exposures to tetrachloroethylene, commonly known as perchloroethylene (PCE) in vapor degreasing (parts cleaning) operations, and to document engineering controls and work practices affecting those exposures.

This study will determine the extent of employee exposures and control technology in industries that utilize vapor degreasing with PCE, thus providing OSHA with data for its analysis of the technological feasibility for a possible revision of the PCE regulations. The study will provide information on: PCE degreasing equipment currently available to industry; engineering controls available to industry, and work practices utilized to reduce employee exposures; use of personal protective equipment; affected industries; maintenance procedures; and the extent of employee exposures. The three most commonly used vapor degreasers include: open-top vapor degreasers (OTVD), in-line vapor degreasers, and vacuum degreasers. The Halogenated Solvents Industry Alliance (HSIA) estimates that approximately $10 \%$ of the 344 million pounds of PCE solvent used in the United States in 1998 was used for metal cleaning/degreasing. ${ }^{1}$ However, the industries using PCE and percentages of degreaser types utilizing PCE are not well defined or are unknown at this time.

The performance of a thorough industrial hygiene survey for a variety of individual employers will provide valuable and useful information to the public and employers in the industries included in the work. NIOSH has conducted 6 sampling surveys at 4 sites to document engineering controls and the associated worker exposures to PCE. The principal objectives of this survey are:

To identify and describe the control technology and work practices in use in degreasing operations associated with potential occupational exposures to PCE, as well as determining additional controls, work practices, substitute materials, or technology that can further reduce occupational PCE exposures.

To measure full-shift, personal breathing-zone exposures to PCE. These samples will provide examples of exposures to PCE among workers across the many industries where PCE degreasing is encountered. These exposure data, along with the engineering control data described above, will provide a picture of the conditions in the selected industries.

\section{PERCHLOROETHYLENE (PCE) HEALTH EFFECTS}

Perchloroethylene is a non-flammable liquid with a molecular structure containing two carbon atoms and four chlorine atoms, a molecular weight of 165.8 (about 5.5 times as dense as air), a 
boiling point of $250^{\circ} \mathrm{F}$, specific gravity of 1.62 , and a vapor pressure of $14 \mathrm{mmHg}$ at $70^{\circ} \mathrm{F}$. Inhalation of perchloroethylene can cause CNS depression (producing symptoms of vertigo, dizziness, nausea, narcosis, in-coordination, headache, if exposures are high enough unconsciousness and death may occur), and direct contact with the liquid may impair the mucous membranes, eyes, and skin. ${ }^{2,3}$ Chronic exposure to perchloroethylene has been reported to cause liver damage and peripheral neuropathy in humans, and liver carcinomas in experimental animals. ${ }^{4}$ The International Agency for Research on Cancer (IARC) position regarding perchloroethylene is that there is insufficient epidemiological evidence to establish the carcinogenic risk to humans. ${ }^{5}$

NIOSH considers perchloroethylene to be an occupational carcinogen, and recommends that exposures be reduced to the lowest feasible level. ${ }^{6}$ The current OSHA permissible exposure limits (PEL) for perchloroethylene are 100 parts per million ( $\mathrm{ppm}$ ) measured as an 8-hour timeweighted average (TWA), $200 \mathrm{ppm}$ ceiling and a maximum peak of $300 \mathrm{ppm}$ for 5 minutes in any three hours. In 1989 OSHA lowered the PEL for perchloroethylene from $100 \mathrm{ppm}$ to 25 ppm, but a 1993 federal court reversed this action. Several states have retained the 1989 limit. The American Conference of Governmental Industrial Hygienists (ACGIH) threshold limit value for PCE is $25 \mathrm{ppm}$ averaged over an 8-hour period, and the 15-minute short-term exposure limit (STEL) is $100 \mathrm{ppm}$. ACGIH lists perchloroethylene as an animal carcinogen (A3) and, based on the available evidence, considers it unlikely to be a human carcinogen, except under uncommon or unlikely routes and levels of exposure. ${ }^{2}$

\section{METAL DEGREASING INDUSTRY BACKGROUND}

Perchloroethylene exposures occur in a large number of industries. Organic solvent cleaning (degreasing) does not constitute a distinct industrial category, but is an integral part of many major industries. The three most commonly used halogenated solvents are methylene chloride, perchloroethylene, and trichloroethylene. In November 1993, the United States Environmental Protection Agency (EPA) published its National Emission Standards for Hazardous Air Pollutants: Halogenated Solvent Cleaning - Background Information Document. ${ }^{7}$ In that document, they report that the five 2-digit Standard Industrial Classification (SIC) codes that use the largest quantities of halogenated solvents for cleaning are SIC 25 (fumiture and fixtures), SIC 34 (fabricated metal products), SIC 36 (electric and electronic equipment), and SIC 39 (miscellaneous manufacturing industries). Additional industries that use halogenated solvents for cleaning include SIC 20 (food and kindred products), SIC 33 (primary metals), SIC 35 (nonelectric machinery), and SIC 38 (instruments and clocks). Non-manufacturing industries such as railroad, bus, aircraft, and truck maintenance facilities; automotive and electric tool repair shops; automobile dealers; and service stations (SIC 40,41, 42, 45, 49, 55, and 75, respectively) also use organic solvent cleaners. The above may also include cold degreasing or metal cleaning operations. In particular, the automobile dealers and service stations would more likely use PCE as a cold degreaser than a vapor degreaser. The EPA estimated that in 1991, there were about 2070 degreasers using perchloroethylene in the U.S. ${ }^{7}$ 
Vapor degreasing is an industrial process used to remove grease, oil, temporary coatings, and dirt or other solids, where clean, dry surfaces are required. The process is commonly used to clean all types of metal and solvent resistant plastics and may be used at any stage of a manufacturing process to clean parts of varying sizes, and parts containing recesses, blind holes, perforations, crevices, or welded seams. Vapor degreasing may occur before: painting, enameling, or lacquering; electroplating; inspection; assembly; or packing. It can also be used before and after machining, before further metal work, or treatment or other special applications. ${ }^{2}$

Due its increased vapor flushing and higher boiling point $\left(250^{\circ} \mathrm{F}\right) \mathrm{PCE}$ solvent is typically used to remove oil and greasy soils which become more fluid and are more soluble at higher temperatures. ${ }^{8}$ Many buffing compounds contain a waxy binder that is only solvent soluble at higher temperatures when it is molten. PCE is the best drying solvent because its high boiling point $\left(250^{\circ} \mathrm{F}\right)$ drives water off the workload rapidly.

\section{THEORY OF PROCESS - Open top vapor degreasers (OTVD)}

Metal parts are cleaned in vapor degreasers by boiling cleaning solvent in the degreaser sump(s), producing a heavy vapor. Cold metal part(s) are introduced to the warm vapor zone causing the solvent vapor to condense on the surface of the cold part(s).

Open-top vapor degreasers consist of several sections:

- A tank - solvent is heated to a boil in the tank.

- The vapor zone - area immediately above the heated tank where vaporized solvent is present. The part(s) to be cleaned are held in the vapor zone until they reach the temperature of the vapor and surface contaminants are flushed off the part(s) by liquid solvent condensation. At this point, condensation or flushing ceases and cleaning is complete. The part is then removed from the unit clean and dry.

- Condensation coils - vapors are condensed on the degreaser condensation coils thereby preventing the vapors from escaping the degreaser. This forms a sharply defined interface between the solvent and air above the coils.

- The freeboard - this is the area between the condensation coils and the top of the degreaser. This area provides additional control in containing the solvent vapor.

The built-in heat balance provides an equilibrium whereby the coil condenses vapors as fast as they are produced by the heaters in the boiling sump. The condensed vapors drip into the collection trough and course through the water separator to the rinse sump and back to the first sump to complete the "Distillate Turnover Cycle."

Vapor degreasers are equipped with water separators to remove water from the process. Water enters a vapor degreaser through condensation of atmospheric moisture. Water in a vapor degreaser increases corrosion and contributes to higher losses because the PCE/water vapor has a lower density then that of dry solvent. The water separator operates on the principle of gravity 
separation, since water is less dense and essentially immiscible in PCE, the water floats to the top. The water is then directed towards disposal while the PCE is returned to the tank sump. ${ }^{8}$

Stills are used to increase recovery of the cleaning solvent. The still can be operated batch-wise or continuously. In continuous operation solvent is fed to the still from the degreaser boiling sump and the distillate returns to the condensate reservoir. A float control is used to keep the level of solvent in the still constant. ${ }^{8}$

Other auxiliary equipment commonly used for OTVDs include: refrigerated freeboard devices to reduce solvent losses and carbon adsorption for removal of solvent vapor from the air. ${ }^{8}$

\section{THEORY OF PROCESS - Airless Vacuum Vapor Degreasers}

This process is performed in an airless, closed vacuum system where cleaning compounds are used in their vapor or liquid state combined with optional spray, tumbling or soaking cycles to completely remove contaminants such as grease, oil, wax or particulate matter from the part surface. Parts to be cleaned are loaded into a preheated degreasing chamber, the chamber is closed, sealed and evacuated. The vacuum achieved is generally less than 5 torr [ 1 torr equals 1 millimeter (mm) Hg]. After pump down, solvent is heated under vacuum pressure to operational temperature and the heated solvent vapor is released from the vapor supply tank into the degreasing chamber. The vapors clean the parts similar to the operations of a traditional vapor degreaser. The warm solvent vapors are condensed on the surfaces of the cooler parts, dissolving soluble contaminants, and carrying them off into the bottom of the degreasing chamber. As the vapor condenses on the parts, the parts heat up until the surface reached the chamber temperature and condensation ceases. If further cleaning is necessary, the parts are sprayed with liquid solvent to cool them down, followed by a second release of vapor into the degreasing chamber. The clean/spray cycle could be repeated as many times as desired. After the cleaning cycles are complete, the solvent recovery process begins. Using a vacuum pump, the liquid solvent and contaminants are drained from the bottom of the degreasing chamber to the distillation chamber. By placing the chamber under a vacuum, virtually all of the remaining solvent is vaporized and removed from the degreasing chamber. The degreasing chamber is then back-filled with ambient air, and pumped down once more, this time passing the exhausted air through a carbon filter to remove traces of PCE before releasing it to the environment. Finally, the chamber is again filled with ambient air to atmospheric pressure and opened for parts removal. Typical cycle times, from parts loading to removal from the degreaser chamber are 20 to 30 minutes. The cleaning process is controlled automatically by a programmable controller, normally requiring no operator attention. ${ }^{10}$

Vacuum or airless vapor degreasers consist of several components: ${ }^{10}$

- Pumps - the pumps are used to reduce the system pressure from 760 torr (atmospheric pressure) down to the operating pressure of less than 5 torr.

- Solvent storage tanks - the solvent storage tank is kept at ambient temperature. The vapor supply tank is maintained at operating temperature $\left(\sim 250^{\circ} \mathrm{F}\right)$. 
- Distillation - stills are used to increase recovery of the cleaning solvent. The distillation column is a jacketed pressure vessel. At low system pressure, the solvent boils at low temperature. Vapors are condensed in the distillation column and a sump at the bottom of the column pumps the contaminants to a waste storage vessel. Waste from the system contains approximately $5 \%$ solvent, conventional open-top vapor degreaser distillation waste contains approximately $30 \%$ solvent.

- Cooling - cooling capacity is need to cool solvent to the liquid form for spraying and to keep solvent storage tank at ambient temperature for efficient pumping.

- Heating - electrical or steam heat is needed to vaporized the solvent.

- Air - is required to operate door lifts, actuate valves, and pneumatic pumps.

- Electrical - electrical requirements are dependent upon whether the unit utilized an electrical boiler, chiller, pumps size, and size of the degreasing vessel.

- Cleaning chamber - part(s) to be cleaned are held in the cleaning chamber until they reach the temperature of the vapor and surface contaminants are flushed off the part(s) by liquid solvent condensation.

\section{STUDY METHODS}

This field study was conducted in accordance with 42 CFR 85a, the NIOSH regulations governing the investigation of places of employment.

\section{INDUSTRY AND PROCESS SELECTION}

A preliminary review of information about degreasing technology was conducted and a plan was then developed to assess worker exposures. The primary criteria for inclusion in this study was the use of PCE as the degreasing solvent, and the use of control technologies to reduce worker exposures. Other criteria used for plant selection were, that the plant be a full-time operation, and that the plant management be willing to participate in the study.

To determine suitability for study, the plant management was contacted by telephone to request participation and to obtain information necessary for scheduling a field visit. Survey participation by facility management and individual employees was entirely voluntary. The selection of the actual survey site was based upon the control technology information received from the facility and any pertinent information received from industry groups, trade associations, or other persons or organizations familiar with the facilities. The intent was to select facilities that appeared to be typical (not necessarily representative) of that specific industry, not the best or the worst. A summary of the study protocol was provided to the plant management in advance of the field survey. 


\section{INFORMATION COLLECTION}

The first day of the site visit was spent meeting with company personnel (company management and employees), conducting a walk through of the plant to begin the industrial hygiene assessment of exposure and control technology used in the degreasing operations, and to arrange sampling on the subsequent day. The initial walk-through survey was intended to characterize potential exposure levels, and to identify workers for full-shift personal sampling. Employees with the highest potential PCE exposures in the degreasing area were the major focus of the site visits and were selected for personal sampling. Workers selected for sampling were briefed on the sampling procedures to be conducted. Because the goal of this study is to assess the effects of engineering controls and work practices on PCE exposures, sample media were placed outside of any respiratory protective equipment worn by the worker.

Pertinent data on the employer and the industry were also collected including; company name and location; number of employees by job title; products produced; processes used, and work schedules. Information about the facility or building(s) included the type of building construction, descriptions of general ventilation present, and age of the facility. Most of this information, while not mandatory for successful completion of the study, was helpful for understanding the operations and processes being sampled.

At the discretion of the industrial hygienist, additional area and/or background samples were collected using NIOSH Manual of Analytical Methods, Method \#1003, photo-ionization detector (PID), or other techniques, if during the course of an investigation it was determined that such measurements would add to the usefulness of the study.

\section{AIR SAMPLING METHODOLOGIES}

This section summarizes the sampling, analytical, and engineering evaluation methods used during the course of this study to measure workplace levels of PCE and methods used to assess the effectiveness of the available control technologies. The effectiveness of the OTVD used at this facility was evaluated primarily by collecting personal breathing-zone (PBZ) air samples for PCE during operation of the vapor degreasers. PBZ samples were collected on the vapor degreaser operator, the assistant operator, the core assemblers (clean room), the brazing furnace operator, and the fan assembly operator.

Personal breathing-zone air samples were collected to determine employees' full-shift, timeweighted average, $\mathrm{PBZ}$ concentrations of $\mathrm{PCE}$. Worker exposures were measured by placing a battery-operated sampling pump on the workers with the air sampler placed in the workers' breathing-zone. Samples were collected at a flow rate of 0.2 liters per minute (lpm) on solid sorbent, coconut shell, charcoal tubes, in accordance with NIOSH Method \#1003. Samples were analyzed for PCE by the NIOSH contract laboratory. 
Sample data sheets were filled out by the field survey team to document all samples collected. Information contained on the sample sheets included: facility name, facility location, process name, worker identifier (included only to allow the "matching" of samples from the same worker on different days), job title and task performed, pump number, pump flow rate, start times, stop times, and sample number. In addition, any unusual conditions, work practices, and use of personal protective equipment, and the number of workers at the facility in that particular job classification, were also noted. Data transmitted to the laboratory included: sample date, sample number, a NIOSH identification code, and a unique sample location code. The identity of the worker corresponding to the sample location codes are known only to NIOSH researchers.

A second set of personal full-shift TWA measurements were collected separately using passive "badge" samplers. This set of measurements consisted of samples collected concurrently with those samples listed above and analyzed via NIOSH Method \#1003. The simultaneous sampling allows for a comparison of the two methods.

\section{CALCULATION OF ANALYTICAL RESULTS}

For each employee sampled, a full-shift (up to 10-hour) TWA exposure to PCE was calculated. Assuming that no exposure occurred during the unsampled period means that the TWA is calculated using the following equation:

$$
T W A=\frac{C_{1} T_{1}+C_{2} T_{2}+\ldots C_{n} T_{n}}{\text { sample time }}
$$

Because most of the samples were single, full-shift samples, when the analysis of a sample results in a value less than the limit of detection (LOD) of the analytical method, the LOD was used to calculate the TWA, and the value(s) are reported as "at or below" the calculated value (e.g., $50.05 \mathrm{mg} / \mathrm{m}^{3}$ ).

When the workday exceeded eight hours, the model developed by Brief and Scala was used to adjust the occupational exposure criteria. The Brief and Scala model results in the calculation of a reduction factor, expressed as:

$$
R F=\frac{8}{h} \cdot\left[\frac{(24-h)}{16}\right]
$$

where RF is the reduction factor and $\mathrm{h}$ is the actual work shift time in hours. The occupational exposure limit (e.g., the REL or TLV) is multiplied by the reduction factor to arrive at an adjusted occupational exposure limit. 


\section{VIDEO EXPOSURE MONITORING}

Video Exposure Monitoring (VEM) is a technique that employs a video camera and a directreading instrument. Synchronization of the internal clocks of both the camera and the instrument is required. For this particular study, the MiniRae 2000 Portable VOC Monitor, Model PGM7600 , (manufactured by Rae Systems Incorporated) served as the direct-reading instrument. The MiniRae 2000 is a compact monitor designed as a broadband volatile organic chemical (VOC) gas monitor and datalogger, capable of storing the data measurements over one-second intervals. It monitors VOCs using a photoionization detector (PID) at an internally integrated flow rate of 450 - 550 milliters per minute $(\mathrm{ml} / \mathrm{min})$. The resulting concentration measurements were downloaded to a notebook personal computer immediately following the sampling session for data storage.

Degreaser operators were monitored during several exposure events using the VEM technique to determine peak exposure events using the MiniRae 2000. Peak exposure events are primarily unloading/loading operations, but could also include repair or maintenance operations which could result in increased PCE exposure (e.g., addition of PCE to the degreaser unit). The MiniRae 2000 was calibrated on-site with a commercially procured $100 \mathrm{ppm}$ isobutylene calibration gas (a surrogate of known proportional response), and operated according to manufacturers instructions. The flow rates for the two MiniRaes used during these surveys were $533 \mathrm{ml} / \mathrm{min}$ and $480 \mathrm{~mL} / \mathrm{min}$.

Each exposure event was monitored for the duration of that event, and for a sufficient time prior and subsequent to establish a background concentration such that 5,10 and 15 minute average exposures can be calculated. As the worker's exposure was being collected, an $8 \mathrm{~mm}$ video camera mounted on a tripod was recording the worker's movements. The exposures were later combined with the videotape and the data appear as a moving bar graph that is superimposed at the edge of the viewing screen. The VEM technique is an excellent tool for illustrating cause and effect relationships in the working environment.

\section{ENGINEERING AND VENTILATION EVALUATION}

A detailed description of the degreasing equipment and auxiliary equipment (e.g. still, carbon filter beds, etc.) were obtained, as well as information about related maintenance operations including the frequency of those operations. Depending on the frequency of the activity and who performs the activity, it may be treated as maintenance activity or as part of the operators' normal activities. Background information about the degreaser including the type of equipment (e.g., OTVD), the equipment manufacturer, the equipment design operation and performance parameters (e.g., automation, enclosure, superheat, distillation unit, carbon absorbers, etc.), ventilation, materials or parts cleaned, maintenance or repair procedures (e.g., still clean-out) and personal protective equipment used (e.g., gloves, respirators) were gathered. Plant and process layout diagrams were obtained from plant management and are included in the attachments. 
Like the information on processes, the summary of engineering controls is a mix of narrative description and physical measurements. The measurements include such items as ventilation flow rates and distance measurements. The proximity of the control systems to open doors or windows, general ventilation intakes and exhausts, and other interacting equipment (i.e., pedestal fans) were also noted. The age and history of the control systems, cost of control installation, maintenance practices, and operation and maintenance costs are included if provided by the facility management.

One technique used to evaluate the effectiveness of the local exhaust ventilation system was the use of a smoke generator. The Rosco, Model 1500 smoke generator was used to visualize airflow patterns at the loading and unloading area of the vapor degreaser. Additionally, airflow measurements were taken across the open section of the vapor degreaser associated with loading and unloading of the vapor degreaser using a VelociCalc Plus, Model 8386 airflow meter.

\section{COMPANY BACKGROUND}

The PCE SITE \#2 is a worldwide group of companies that was founded in 1919 and currently employs more than 1,600 people. The company is located in the southeast and was incorporated in 1981. It is a leading manufacturer of brazed aluminum heat exchangers and cooling systems, serving off-highway, on-highway, industrial, mining, and other markets. The company specializes in developing custom aluminum cooling systems that satisfy cooling requirements for air, oil, diesel fuel, and water/glycol applications. The company manufactures custom designed, brazed aluminum, air-cooled heat exchangers for: adiators; Oil coolers - transmission, hydraulic, compressor, lube oil; Charge Air Coolers; Compressed Air Coolers; Fuel Coolers; supplies individual coolers or complete systems including fan, motor (hydraulic, electric, air driven), finger guard, and shroud.

\section{VAPOR DEGREASING (Cleaning) PROCESSES}

The cleaning of parts is necessary to remove dirt and oils from metal parts prior to assembly processes. The vapor degreaser used at Site $\# 2$ is located in the Core Assembly building of the facility (see Diagram A, floor plan). The company utilizes a Finishing Equipment Vapor Degreaser Model AE-2-0-SP DEGREASER, Serial No. 6180, for its parts cleaning operation. The vapor degreaser unit utilized in this operation is an open-top (batch degreaser) unit. The vapor degreaser is equipped with: a top enclosure; a hoist for automated handling; a still (AS-30 STILL, Serial No. 6181); a chiller (ACC-30 CHILLER SYSTEM, Serial No. 6182); a water separator; a solvent recovery treatment (SRT) system; an auxiliary heating (electric) system; and local exhaust ventilation. (see diagram $B$, vapor degreaser drawing).

The loading/unload station is equipped with local exhaust ventilation (LEV). The LEV is designed to capture and remove PCE vapors to prevent the escape and subsequent worker 
exposures at the loading/unloading station. Additional exhaust would result in greater solvent losses from the degreaser unit. Therefore, only the loading/unload station of the degreaser is exhausted to prevent solvent losses. The loading/unloading station opening is 46 inches (height), 76 inches (width) and 38 inches (depth).

The vapor degreaser cleaning cycles are computer controlled, both the rate at which the load enters and exits the vapor degreaser, and the cycle times are factory set. The degreaser crane is programmed to travel at a rate of 11 feet per minute (FPM) to prevent dragout and displacement of PCE vapors. ${ }^{9}$ The degreaser is programmed to run three time cycles (12-13 minutes, 10-11 minutes, and 26-27 minutes).

The vapor degreaser has three sumps for boiling solvent to create PCE vapor. The vapor created is several times heavier than air and is condensed on the circumferential condensing coil. The condensed distillate is collected in a trough below the coil. The collecting trough is sloped to one end to collect solvent condensate which flows via gravity to the water separator. The water separator discharge flows to the second dip sump which overflows to the first dip sump, which flows to the distillation sump for cleaning and recycling. ${ }^{9}$

The degreaser operator and assistant operator manually load parts into baskets, move the loaded basket into the loading station, attach the basket to a crane and operate the computer control panel. The cleaning basket is automatically hoisted and moved via monorail over two PCE sumps. The parts basket is then lowered and immersed in the first sump, followed by immersion in the second sump. The cleaning cycle time is dependent on the parts to be cleaned. After cleaning the parts, the basket is reversed and brought back to the loading station to be unloaded.

The vapor degreaser is equipped with a safety vapor cutoff and a vapor up control. The safety vapor cutoff is a sensing capillary bulb located above the condensing coils. This safety control is designed to shut down the heating elements if PCE vapors rise above the condensing coils, due to inadequate cooling. ${ }^{\text {? }}$

The vapor up control, while not a true safety control is intended to prevent improper operation of the vapor degreaser. A thermocouple, which is a few inches below the normal vapor line, senses the presence of true vapor. This control is interlocked with various important functions to prevent their operation if the vapor line is not at its proper level. ${ }^{9}$

\section{SOLVENT}

A stabilized solvent is used to prevent chemical breakdown of solvent and subsequent acid formation. Over time, solvent stabilizers are depleted. To prevent acid formation the $\mathrm{pH}$ of the degreaser PCE must be tested weekly and chemical stabilizers added as needed. Acid formation in the degreaser will cause many potential problems necessitating shut down of the unit for cleanout and repair. 


\section{EMPLOYEE RESPONSIBILITIES}

The cleaning of parts is necessary to remove dirt and oils from the aluminum parts prior to assembly and furnace brazing. The degreasing operation at this facility runs two 10-hour shifts. The degreaser operator and assistant operator place the parts to be cleaned onto racks, or directly into cleaning baskets. The cleaning basket is placed on a wheeled cart for transport to the loading station. The cart is moved into the loading station and the basket is attached to the hoist chains. The operator or assistant then sends the parts basket through the automated degreaser unit using the computer control panel. As previously mentioned, the cycle times are dependent on the parts being cleaned. During the cleaning cycle the worker(s) leave the loading/unloading station to prepare loads for cleaning or to unload the previously cleaned parts. Theoretically, the cleaned parts should be dry when removed from the degreaser unit. The degreaser operator and assistant operator typically spend about one and one-half to two hours per shift at the loading/unloading station; the remainder of their day is spent placing parts onto racks, removing cleaned parts from the cleaning baskets, and transporting cleaned parts to the "clean room." The second shift degreaser operator has the added responsibility of adding PCE to the vapor degreaser unit. Typically, one 55-gallon drum is added to the unit every one to two weeks. Cleaned parts are removed from the cleaning baskets by hand and placed in 55-gallon plastic containers or on storage shelves. After cooling, the cleaned parts are transported to the "clean room" on wheeled carts.

The "clean room" is an enclosed room on the east central side of the building (see diagram A). The room is equipped with a separate air handling system using $100 \%$ recirculated air from the building. Clean room employees (core assemblers) assemble the heat exchangers. The core units are assembled by placing the individual parts on a rack and bundling each unit together. The finished unit is sent to brazing furnace. The core assemblers spend $100 \%$ of their time in the clean room assembling heat exchangers. They typically assemble about 25-30 units per shift per worker.

\section{BUILDING VENTILATION}

General ventilation in the building housing the vapor degreaser was provided by three industrial exhaust fans manufactured by Dayton Electric Manufacturing Company. Two 30-inch diameter fans and a 36-inch diameter fans. The 30-inch fan on the south side of the building, next to the QC office, was approximately thirteen feet above floor level. A second 30-inch fan was on the east side of the building behind the degreaser, seven feet above floor level. The larger 36-inch fan was on the north side of the building behind the vacuum brazing fumace, approximately three feet above floor level. During the warm weather months all overhead and side doors are kept open and all three exhaust fans are kept running to provide maximum ventilation inside the building. During cold weather months the building is provided minimum ventilation to conserve energy. The outside doors and windows are kept closed and only the 30 -inch wall fan behind the degreaser is operated. 
The vapor degreaser is equipped with a local exhaust ventilation (LEV) system consisting of an exhaust fan, a 12-inch diameter duct and a 30-foot high roof stack. During normal vapor degreaser operation the LEV system is continuously exhausting air from the loading station to the outdoors.

The clean room is equipped with separate, dedicated ventilation system which operates independently from the building ventilation system. The primary function of the clean room is to keep the parts dust-free during assembling of the heat-exchanger components. The clean room air is continuously filtered with $99.97 \%$ high efficiency particulate filters with pre-filters to ensure dust-free environment. The clean room is maintained under a positive barrier relative to the overall building in order to prevent cross-contamination of the room during incoming and outgoing traffic.

\section{RESULTS AND DISCUSSION}

Two sampling surveys were conducted at this facility. Following the initial survey (January 2001) the vapor degreaser was scheduled for maintenance to control or reduce degreaser emissions. To compare worker exposures before and after completion of the maintenance operations a second survey (April 2001) was conducted. Personal sampling data were collected to characterize worker exposure levels and the associated control technology used for this OTVD.

\section{January 2001, Site Survey - PCE Sampling Results}

On January 22-26, 2001, personal breathing-zone air samples and passive dosimetry samples were collected on the degreaser unit operators and other employees working in the Core Building, where the degreaser unit is housed. Additionally, Video-Exposure Monitoring (VEM) of cleaning cycles was conducted. At the time of the survey, no maintenance operations were conducted.

Table 1 presents the results of personal sampling for PCE during the January, 2001 sampling survey. The sample results are compared to the Brief and Scala adjusted criteria because the employees worked an extended 10-hour work shift.

Sampling was conducted during the first shift on January 23 and 24, and during the second shift on January 25, 2001. On January 23, samples were collected on workers from the start to the end of the first shift. On January 24 , samples were collected in the morning until workers opened the plant doors and windows, at which time the sample media was exchanged for fresh sample media. The change was made to differentiate air concentrations associated with the building closed versus air concentrations when the plant windows and doors opened to the outdoor air. During the January mornings, the outdoor air was cold and the workers would keep the plant windows and doors closed to maintain a comfortable indoor temperature, as the outdoor air 
warmed up around mid-morning the workers would open the plant doors and windows. It was reported that this is standard practice of the workers in this building.

Sample results indicate that the airborne PCE concentrations in the morning - when the plant was closed with respect to the outdoor air - were roughly double the airborne PCE concentrations when the doors and windows were opened. The PCE charcoal tube concentrations for employees working in the open areas of the building (excludes core assemblers in the clean room) ranged from 33.1 parts per million (ppm) to $40.8 \mathrm{ppm}$ during the morning sample period, and from 16.3 ppm to $22.4 \mathrm{ppm}$ during the afternoon sample period. Outdoor air entering the building through opened doors and windows, provided natural ventilation to the open areas, thereby diluting PCE concentrations during the second half of the shift. The only exception noted is the sample collected on the core assembler working in the "clean room." However, this sample should not be directly compared with the samples in the open plant areas for purposes of explaining the differences associated with closed plant versus open plant samples. Due to the fact that the "clean room" is an enclosed room that is kept closed with respect to the outside environment and other areas of the building. The windows and doors of the "clean room" cannot be opened with respect to the outdoor air, the doors to the room do not open to the outdoors, the doors from the adjacent areas of the plant are kept closed, and the room is equipped with an air handiing system dedicated to that room.

When comparing TWA concentrations over the entire sample period it becomes evident that the airborne concentrations were highest on the first day of sampling. Concentrations ranged from $26.2 \mathrm{ppm}$ to $37.8 \mathrm{ppm}$. The second day concentrations ranged from $23.8 \mathrm{ppm}$ to $32.1 \mathrm{ppm}$. The difference could be directly related to the amount of time the plant was opened up to the outdoor air. The third day concentrations ranged from 20.8 to $23.8 \mathrm{ppm}$. The lower concentrations on the second shift would be related to the fact that the PCE concentrations were not allowed to accumulate because the building was opened to the outdoor air the entire shift. An analysis of variance shows that the differences (when comparing plant open versus plant closed, with respect to the outdoor air) are statistically significant, please see the discussion of statistical results.

\section{January 2001, Site Survey - Observations}

During the walk-through survey a strong odor of the PCE was present throughout the core assembly building, indicating that the engineering controls were not effective in purging PCE from the building. It was noted the wall fan behind the vapor degreaser was operating and that the door on the north side of the building between the vapor degreaser and the vacuum brazing furnace was open. This provided natural ventilation to the vapor degreaser area only, not the entire building, leading to the formation of dead spaces throughout the entire building. These dead spaces entrap and accumulate escaped PCE vapors, making it very difficult for the general ventilation to successfully remove them from the building. The PCE concentrations measured in the building, during this survey ranged from 21 to $38 \mathrm{ppm}$. 
TABLE 1

Perchloroethylene (PCE) Degreaser Study - Site \#2

Sample Results

January 2001

\begin{tabular}{|c|c|c|c|c|c|c|c|c|}
\hline \multirow[t]{3}{*}{ Date } & \multirow{3}{*}{$\begin{array}{c}\text { Job/Location } \\
\text { First Shift } \\
\end{array}$} & \multirow{2}{*}{\multicolumn{3}{|c|}{$\begin{array}{l}\text { Sample Time } \\
\text { (minutes) }\end{array}$}} & \multicolumn{4}{|c|}{ PCE Concentration (ppm) } \\
\hline & & & & & \multicolumn{3}{|c|}{$\begin{array}{c}\text { Charcoal } \\
\text { Tube }\end{array}$} & \multirow{2}{*}{$\begin{array}{c}\begin{array}{c}\text { Passive } \\
\text { Dosimeter }\end{array} \\
\text { Total } \\
\end{array}$} \\
\hline & & $\mathbf{A M}$ & PM & Total & $\mathbf{A M}$ & $\mathbf{P M}$ & Total & \\
\hline $1 / 23$ & Degreaser Operator & & & 554 & & & 37.8 & 36.8 \\
\hline $1 / 23$ & Degreaser Assistant & & & 564 & & & 36.2 & 34.1 \\
\hline $1 / 23$ & Core Assembler & & 2. & 557 & & Hent & 34.4 & 34.5 \\
\hline $1 / 23$ & Fan Assembler & & $a^{2}$ & 536 & & 4 & 26.2 & 25.3 \\
\hline $1 / 23$ & Vacuum Furnace Operator & & 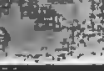 & 507 & & W. & 31.9 & 29.0 \\
\hline $1 / 24$ & Degreaser Operator & 307 & 260 & 567 & 40.8 & 19.6 & 31.1 & 31.9 \\
\hline $1 / 24$ & Degreaser Assistant & 310 & 267 & 577 & 40.4 & 22.4 & 32.1 & 31.4 \\
\hline $1 / 24$ & Core Assembler & 304 & 259 & 563 & 22.6 & 27.6 & 24.9 & 24.1 \\
\hline $1 / 24$ & Vacuum Furnace Operator & 216 & 288 & 504 & 33.1 & 16.9 & 23.8 & 22.5 \\
\hline \multirow[t]{2}{*}{$1 / 24$} & Fan Assembler & 184 & 285 & 469 & 39.7 & 16.3 & 25.5 & 24.1 \\
\hline & Second shift & & & Total & & & Total & Total \\
\hline $1 / 25$ & Vacuum Furnace Operator & 278 & 97 & 375 & 24.1 & 17.5 & 22.4 & 22.6 \\
\hline $1 / 25$ & Degreaser Operator & 280 & 249 & 529 & 29 & 18.1 & 23.8 & 23.5 \\
\hline $1 / 25$ & Core Assembler & & 172 & 529 & & 21.9 & 21.9 & 21.4 \\
\hline $1 / 25$ & Core Assembler & 354 & & 527 & 20.8 & & 20.8 & 21.3 \\
\hline \multicolumn{5}{|c|}{ Brief and Scala - Adjusted Criteria for PCE } & 70 & 70 & 70 & 70 \\
\hline \multicolumn{5}{|c|}{ OSHA 8-hour - Time Weighted Average for PCE } & 100 & 100 & 100 & 100 \\
\hline
\end{tabular}


On Monday evening (January 22), after the walk-through survey the second shift degreaser operator added one 55-gallon drum of PCE to the vapor degreaser, to prevent burning out the still heating elements. It was reported that the vapor degreaser typically uses about 55 gallons of PCE every one to two weeks.

The PCE vapor degreaser at this facility is equipped with a still which separates or removes contaminants from the PCE solvent by distillation. The cleaned PCE is then recycled to the degreaser unit. Normally the still is operated in the continuous mode, but due to a malfunctioning liquid level sensor the still was purposely shut down, during the January site survey. The liquid level sensor is a float control that measures the solvent level in the still. If the solvent level is too low the liquid level sensor automatically shuts down the still to prevent damage to the heating element. According to the department supervisor the still is occasionally shut down or purposely not used, but this has "no effect on the operation of the degreaser."

A plant floor layout is provided in the Appendix to this report as Diagram A. This diagram provides various measurements, such as distance from adjacent operations. A diagram of the vapor degreaser is also provided in the Appendix as Diagram B. This diagram provides physical measurements degreaser unit including the unloading/loading station. PCE sampling data collected by the company are also provided in the Appendix.

\section{Maintenance Operations between surveys}

In early February, about one week after the first sampling survey a total clean-out of the PCE vapor degreaser was conducted. This routine maintenance operation is conducted about once every 9 to 12 months and is necessitated by the chemical breakdown of PCE and the build-up of waste within the vapor degreaser solvent. The cleanout operation involves removing used PCE from the unit, cleaning the degreaser interior and refilling the degreaser unit with clean PCE. A firm specializing in degreaser cleanouts is contracted to conduct the cleanout operation. This cleanout operation was actually scheduled to be performed in March, but due to the malfunctioning liquid level sensor the schedule was moved up to get the unit to operate more efficiently.

According to the maintenance contractor a concentration of $20-30 \%$ oil in the solvent indicates that the solvent should be replaced and the unit should be cleaned. It was indicated that the liquid level sensor was sticking due to excessively dirty solvent. The vapor degreaser still was not well maintained as evidenced by excess oil in still, oil in the water separator, and the unit was using about 55 gallons of PCE per week

In early April another problem with the degreaser became evident. The degreaser chiller, flow switch kept tripping indicating a problem with the chiller. It was determined that microbial growth in the chiller pipes was resulting in restricted fluid flow through the chiller. The coolant fluid temperature entering the chiller versus the exiting temperature was not the recommend 
difference, indicating reduced cooling capacity of the chiller. Plant records indicated that the degreaser coolant had never been changed from the time the unit was installed in 1996.

\section{April 2001, site survey - PCE Sampling Results}

On April 9-12, a return visit was conducted to collect PBZ air samples for PCE following two maintenance operations intended to improve the performance of the vapor degreaser. To determine if the maintenance operations had an affect on the efficiency of the vapor degreaser and amount of PCE escaping from the unit, a second site visit was conducted. Personal breathing-zone samples and passive dosimetry samples were collected on the degreaser unit operators and other employees working in the core assembly building. Additionally, videoexposure monitoring of cleaning cycles was conducted. During the survey, no maintenance operations were conducted.

Table 2 presents the results of personal sampling for PCE during the April 2001, sampling survey. Again, the sample results are compared to the Brief and Scala adjusted criteria because the employees worked an extended 10-hour work shift.

When comparing sample results to the January survey it becomes readily apparent that PCE concentrations were much lower during the April survey. Full shift, charcoal tube sample results (April 9-10) ranged 6.6 to $13.0 \mathrm{ppm}$, compared to 20.8 to $37.8 \mathrm{ppm}$ (January 23-25). However, a closer look at the data reveals that the contrast is not as sharp as it appears, although it also represents a significant decline in employee exposures. Because all the plant doors and windows were open, the April data is more directly comparable to data collected on the afternoons of January $24^{\text {th }}$ and $25^{\text {th }}$, when similar conditions existed (i.e., open doors and windows). Charcoal tube results for workers in the open area of the building (excludes core assemblers in the clean room) from $6.6 \mathrm{ppm}$ to $12.7 \mathrm{ppm}$ during the April survey, compared to $16.3 \mathrm{ppm}$ to $22.4 \mathrm{ppm}$ on afternoons of January $24^{\text {th }}$ and $25^{\text {th }}$.

At the beginning of the second shift on the evening of April $9^{\text {th }}, \mathrm{PBZ}$ samples were collected on the degreaser operator to determine his exposure during the addition of one 55-gallon drum of . PCE to the degreaser unit. Sampling results individual indicated that his exposure was $3.1 \mathrm{ppm}$ for the 23 minute operation. The operator wore a 3M 7361 half-face respirator equipped with a 3M 6001 organic vapor cartridge. As indicated earlier all samples for this study were collected outside any personal protective equipment used by the workers. The degreaser operator used a dolly to wheel the 55-gallon drum of PCE to the vapor degreaser and connected a hose between the vapor degreaser and the drum. A compressed air pump was used to transfer PCE to the vapor degreaser. After connecting the hose to the drum the worker left the area to conduct other duties and returned about 15 minutes later to disconnect the hose from the drum. Overall, the operation took about 23 minutes to complete, but the worker spent about four minutes connecting and disconnecting the hose from the drum, the remainder of his time was spent doing other duties away from the immediate vicinity of the degreaser. 


\section{TABLE 2}

Perchloroethylene (PCE) Degreaser Study - Site \#2

Sample Results

April 2001

\begin{tabular}{l|l|c|c|c}
\hline \hline \multirow{2}{*}{ Date } & \multicolumn{1}{|c|}{ Job/Location } & \multirow{2}{*}{$\begin{array}{c}\text { Sample Time } \\
\text { (minutes) }\end{array}$} & & \multicolumn{2}{|c}{ PCE Concentration (ppm) } \\
\cline { 4 - 5 } & & & Charcoal Tube & Passive Dosimeter \\
\hline \hline $4 / 09$ & $\begin{array}{l}\text { Degreaser Operator - } \\
\text { adding PCE to the unit }\end{array}$ & & 3.1 & 4.4 \\
\hline \hline $4 / 10$ & Degreaser Operator & 550 & 12.7 & 12.8 \\
\hline $4 / 10$ & Degreaser Assistant & 568 & & 12.4 \\
\hline $4 / 10$ & Core Assembler & 561 & 12.8 & 12.9 \\
\hline $4 / 10$ & Core Assembler & 569 & 13 & 13.3 \\
\hline \hline $4 / 11$ & Degreaser Operator & 565 & 10.6 & 11 \\
\hline $4 / 11$ & Degreaser Assistant & 575 & 11.9 & 10.2 \\
\hline $4 / 11$ & Core Assembler & 569 & 10.9 & 10.5 \\
\hline $4 / 11$ & Core Assembler & 572 & 12.1 & 10.3 \\
\hline $4 / 11$ & Core Assembler & 572 & 11.1 & 10.9 \\
\hline $4 / 11$ & Fan Assembler & 489 & 6.6 & 6.5 \\
\hline \hline Brief and Scala - Adjusted Criteria for PCE & $\mathbf{7 0}$ & $\mathbf{7 0}$ \\
\hline OSHA 8-hr. - Permissible Exposure Limit for PCE & $\mathbf{1 0 0}$ & 100 \\
\hline
\end{tabular}




\section{April 2001, site survey observations}

The PCE sampling results indicate that the overall worker exposures decreased from the time of the first survey. As discussed earlier, this is probably due to a combination of the plant doors and windows being opened by the workers to provided natural ventilation, and improved maintenance of the vapor degreaser.

It appeared that the cleaning basket (during cycle \#3) was not entirely within the cooling zone of the primary condenser coils (see Diagram C). The upper half of the basket was situated in the freeboard area while the lower half of the basket was in the cooling zone. It is likely that this situation may result in the release of excess PCE from the vapor degreaser and may be responsible for fugitive emissions. If corrected, this could possible result in even lower PCE concentrations within the area of the vapor degreaser and the adjacent areas.

During the first survey, it was recommended that the break area be moved out of the building housing the degreaser and it was noted that the plant management had immediately implemented this recommendation.

\section{STATISTICAL RESULTS}

An analysis of variance was carried out to make two comparisons based on sixteen charcoal tube determinations. It must be noted that the data points for the Core Assemblers on both January 24 and 25, 2001 are excluded in these analyses, because the Core Assembly Room was a separate enclosed area not open to the outside air, as were the areas surrounding the vapor degreaser where the other samples were collected. The first analysis is a comparison of PCE concentrations within the building when the building doors and windows were closed versus PCE concentrations when the doors and windows were open (Graph 1 - Closed Building vs. Open Building). Data pairs were collected during the mornings (building closed) and afternoons (building open) of January $24^{\text {th }}$ and $25^{\text {th }}$. The second analysis is a comparison of PCE concentrations measured during the January survey versus the April survey (Graph 2 - Open Building vs. Open Building), specifically, open building PCE concentrations on the afternoons of January $24^{\text {th }}$ and $25^{\text {th }}$ versus open building PCE concentrations on April $10^{\text {th }}$ and $11^{\text {th }}$. The second analysis was conducted to determine if maintenance operations performed on the vapor degreaser, between the January and April surveys, may have affected on the performance of the vapor degreaser unit. In addition to differences involving the study variables, the statistical model considered differences between jobs, workers, and days. Results were averages over the three variables (jobs, workers, days).

The estimated ratio for the first analysis (building open versus building closed) was less than 0.55 , and the estimated ratio for the second analysis (before maintenance versus after maintenance) was also less than 0.55 . The results of both analyses were statistically significant in one-sided Student's $t$ tests at the 5\% significance level. These are average results and vary 

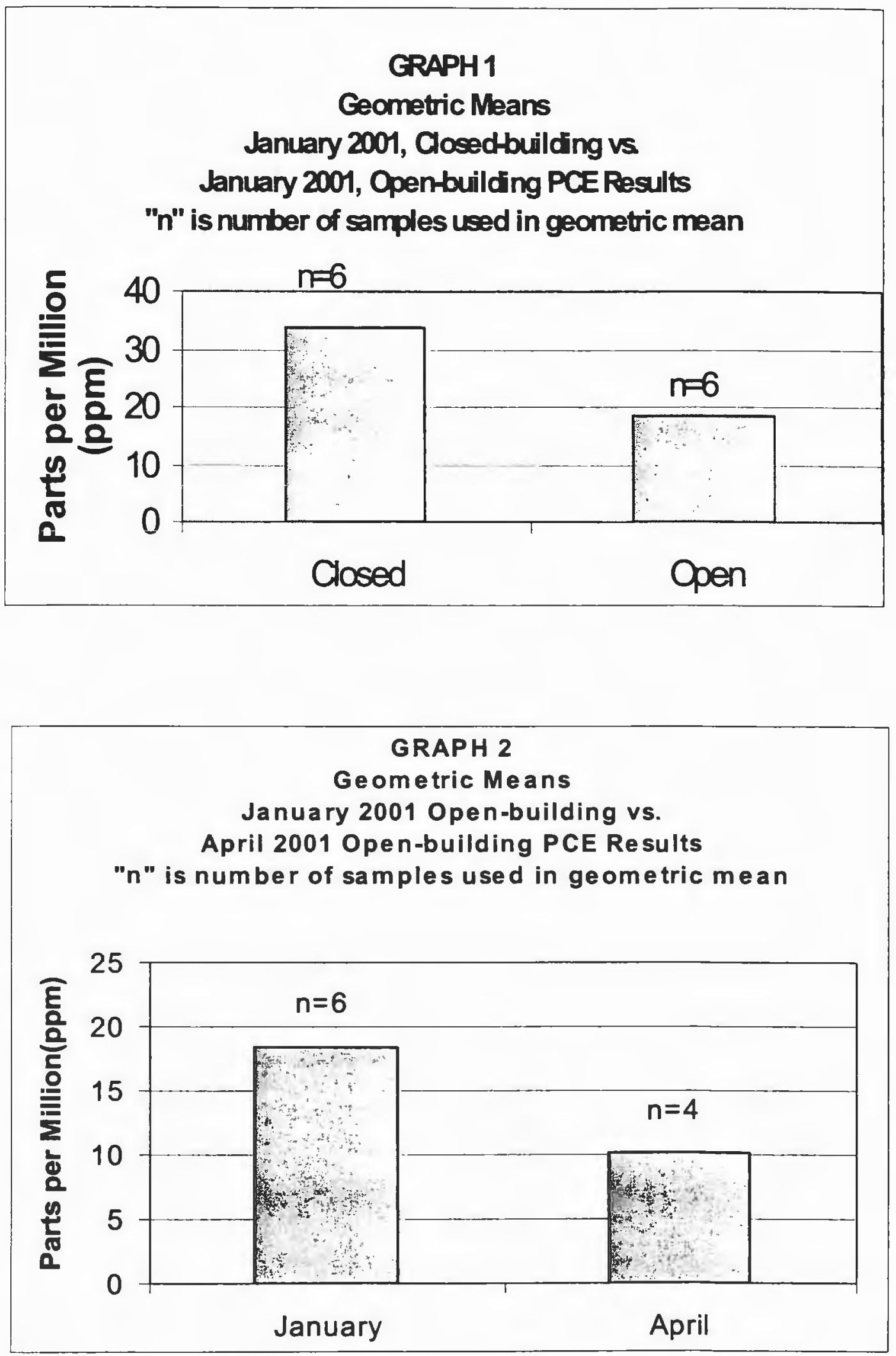
somewhat with the job. Also, the statistical statements apply just to these jobs, workers, and days of sampling at this particular site, rather than to a larger population.

\section{VENTILATION RESULTS}

A smoke machine was used to visualize and characterize air flow patterns near the loading/unloading station of the vapor degreaser. The smoke test revealed some air flow problems. Air at the vapor degreaser loading/unloading opening was slightly turbulent, with some eddy formation near the wall of the loading and unloading area, resulting in contaminated air moving into the breathing zone of the operator. These adverse flow patterns appear to be caused by the presence of air drafts near the loading and unloading station, resulting from the use of large portable fans by the employees. During this survey, the airflow measured upstream of the exhaust fan was $6200 \mathrm{cfm}$ and the airflow measured across the loading/unloading zone was $1500 \mathrm{cfm}$. According to the vapor degreaser design specification the unit should be exhausting around $2000 \mathrm{cfm}$. The above data indicate the vapor degreaser was exhausting approximately three times more then designed.

\section{VENTILATION DISCUSSION}

The locations of the wall exhaust fans in core assembly building significantly limited their ability to provide uniform ventilation throughout the building. The smoke machine used to visualize airflow patterns in the building showed that the overall ventilation within the building was poor. The smoke test revealed that most of the makeup air entering the facility was short circuited to the outdoors, thus preventing uniform displacement of the air inside the building. The number of air changes were greatest near the building wall fans, while the number of air changes observed near the center of the building and near the ceiling were minimal.

Options for overcoming the operational deficiencies in the general ventilation of the core building are discussed below. Relocation of the exhaust fans to a central location near the ceiling should minimize short circuiting of makeup air to the outdoors and ensure a more uniform delivery of the makeup air throughout the building, thus diluting PCE concentrations in the building and thereby reducing worker exposures. Implementation should occur as following: 1) the first step should be to relocate the existing wall fans to the center of the ceiling; 2) the second step should be to maximize the capacity of the existing fans by upgrading the pulleys and electrical motors. Should the second step prove to be unsuccessful in providing proper ventilation to the core assembly building, the third step should be to replace the existing fans with new larger capacity fans.

During this survey it was observed that the wall fans were poorly serviced and maintained. Preventive maintenance and servicing of the ventilation equipment is essential for ensuring optimum performance. Extreme wear and tear was observed on most of the fan belts in the core assembly building. For example, the fan belt of the wall exhaust fan located behind the vapor degreaser was in very poor condition, continuously slipping, resulting in reduced fan 
performance. It is essential that the existing maintenance programs be appropriately modified in accordance with the manufacturer guidelines to ensure proper upkeep, minimum downtime and a efficient operation of this ventilation equipment.

Proper operation and maintenance of the vapor degreaser local exhaust ventilation system is critical for ensuring minimum consumption of the PCE during daily use of the vapor degreaser. As mentioned in the preceding section, the airflow measured upstream of the vapor degreaser exhaust fan was $6200 \mathrm{cfm}$. The vapor degreaser drawing provided to the company by the manufacturer of the unit indicated that the unit should be exhausting approximately $2000 \mathrm{cfm}$. The above data indicate the vapor degreaser was exhausting approximately three times more then designed. If too much exhaust is removed from the loading station, it will cause excessive loss of PCE vapors from the vapor degreaser resulting in high PCE consumption. If too little exhaust is removed from the loading zone it will cause PCE vapor to escape from the vapor degreaser into the work environment, thus increasing worker exposures. Therefore, it is critical the vapor degreaser be operated at optimum flow-rate across the loading and unloading zone to ensure minimum consumption of the PCE.

\section{CONCLUSIONS}

The sampling results indicate that the employees working in core assembly building were not exposed to PCE in excess of the OSHA PEL. However, most PBZ concentrations exceeded the ACIGH TLV of $25 \mathrm{ppm}$ during the January survey when the building doors and windows were closed. The PCE concentrations in the building could be reduced through proper preventive maintenance (see Recommendations section).

While not discussed in detail the passive dosimeter samplers provided results similar to the results of the charcoal tube analyses. A separate publication on the comparison of these two methods will be prepared and will be provided to the company when published.

\section{RECOMMENDATIONS}

The following recommendations are offered to improve working conditions within the core assembly building and to reduce PCE concentrations and subsequent employee exposures. A professional ventilation engineering firm should be consulted to determine which options for improving general ventilation in the core assembly building would be most feasible from a technical and economical standpoint.

1. To minimize the influence of the immediate environment on the operation of the vapor degreaser the unit should be located in a "draft-free position away from windows, doors, heater blowers, and air intakes. Drafts must not blow into the load/unload area." The use of fans near the load/unload station disturb air flow into the local exhaust ventilation 
unit at this station and interfere with the efficient collection of fugitive emissions from the unit and should be removed from the area near.

2. The degreaser unit should also be located away from or isolated from heat sources, specifically the brazing furnace. The presence of heat sources near unit can react with PCE emissions forming other hazardous substances. The Material Safety Data Sheet provided by the PCE distributer states that "This product may decompose when it comes in contact with open flames, heating elements, electrical arcs (such as electrical motors) or combustion engines." The MSDS further states that "Decomposition by-products may include chlorine, hydrogen chloride, carbon monoxide, carbon dioxide, and possible traces of phosgene."

3. Employees involved in degreaser clean-outs should be sampled to determine exposure levels associated with degreaser clean-out operations.

4. The degreaser crane and cable length should be properly adjusted to insure that the entire cleaning basket is within the cooling zone (condenser level) to prevent release of excess PCE from the degreasing unit, please see discussion (page 20).

5. The current preventive maintenance schedule does not appear to be adequate to insure proper operation of the vapor degreaser. Preventive maintenance and routine maintenance are key ingredients to proper operation of the vapor degreaser. The results of the second sampling survey suggest that the two maintenance operations conducted between the NIOSH sampling visits resulted in lower airborne PCE concentrations after the total clean-out of the vapor degreaser and the chiller piping, please see discussion (page 16-17).

6. Comprehensive employee education is a key to proper operation and maintenance of the vapor degreaser. Degreaser operators should be trained, not only in the operation of the vapor degreaser, but also on recognizing when preventive maintenance is indicated so that they can alert the department supervisor when necessary. The degreaser operators should receive annual training to insure that the vapor degreaser operates at maximum efficiency.

7. According to the cleanout contractor a concentration of $20-30 \%$ oil in solvent indicates that the solvent should be replaced and the unit cleaned out. Degreaser operators should be trained to recognize and test the solvent to insure that the concentration of oil in the solvent does not exceed this level.

8. Relocation of the wall exhaust fans to a central ceiling location should improve and ensure uniform air distribution throughout the core assembly building. Relocating the exhaust fans to a central ceiling location should also improve the make-up air distribution provided to the building (by providing natural ventilation). The amount of make-up air 
can be easily regulated through opening and closing of doors in the areas where make-up air is required or closed when not required.

9. To ensure optimum performance of the wall exhaust fans, all fan belts should be inspected on a weekly basis and replaced if they show signs of deterioration or slippage.

10. During warm weather months when all of the overhead and side doors to the core assembly building facility are open to provide natural ventilation, there is adequate makeup air available for ventilation of the building. However, during the cold winter months the amount of make-up air provided to the building is limited, to conserve energy, by keeping the building doors and windows closed. Three options for providing make-up air to the building during the cold winter months follow. In the first option, the outside air entering the building can be preheated with exhaust air exiting the building using an air-to-air heat exchanger. Maintenance of the heat exchanger would be required with this option. In the second option, the vapor degreaser area would be enclosed and the air recirculated through charcoal filters to capture the PCE released during daily operation of the vapor degreaser. This would require regular maintenance including replacement of the charcoal filter bed. The third option would provide ducted make-up air to the building with no air-to-air heat exchanger. This would have a lower initial cost, lower maintenance costs, but higher operating costs. As previously mentioned, these options should be explored in-depth with an experienced industrial engineering ventilation consultant and the proper option implemented after considering the trade-offs and practicalities before changes are made.

11. The manufacture of the vapor degreaser should be contacted to determine the proper exhaust rate for the loading/unloading station. The data collected indicates that the vapor degreaser exhaust rate was approximately three times more than designed. Airflow measurements collected during the survey indicated that the exhaust rate upstream of the vapor degreaser exhaust fan was $6200 \mathrm{cfm}$, while the vapor degreaser drawings provided indicate that the unit should be exhausting around $2000 \mathrm{cfm}$. 


\section{REFERENCES}

1 HSIA [1999]. Perchloroethylene White Paper. Halogenated Solvents Industry Alliance, 2001 L. Street, NW - Suite 506A, Washington, D.C. 20036.

2. ACGIH [1986]. Documentation of threshold limit values and biological exposure indices for chemical substances and physical agents. Cincinnati, $\mathrm{OH}$ : American Conference of Governmental Industrial Hygienists.

3. NIOSH [1976]. Criteria for a recommended standard: Occupational Exposure to Perchloroethylene. Cincinnati, OH: U.S. Department of Health, Education, and Welfare, Public Health Service, Center for Disease Control, National Institute for Occupational Safety and Health, DHEW (NIOSH) Publication No. 76-185.

4. Proctor NH, Hughes JP, Fischman ML [1988]. Chemical hazards of the workplace. Second Edition. Philadelphia, PA: J.B. Lippincott.

5. LARC [1982]. IARC monographs on the evaluation of the carcinogenic risks of chemicals to humans, supplement 4. Lyon, France: International Agency for Research on Cancer.

6. NIOSH [1992]. Recommendations for occupational safety and health: compendium of policy documents and statements. Cincinnati, OH: U.S. Department of Health and Human Services, Public Health Service, Centers for Disease Control, National Institute for Occupational Safety and Health, DHHS (NIOSH) Publication No. 92-100.

7. EPA [1995]. Halogenated Solvent Cleaning National Emissions Standards For Hazardous Air Pollutant Background Information Document. Research Triangle Park, NC: U.S. Environmental Protection Agency. EPA Order Number: EPA453 R94071.

8. Vapor Degreasing Handbook [1987]. Occidental Chemical Corporation, Electrochemicals Division, Occidental Tower, 5005 LBJ Freeway, Dallas, Texas, 75244.

9. Finishing Equipment Vapor Degreaser Model AE-2-0-SP Degreaser Manual [1996]. Finishing Equipment, Inc., 3640 Kennebec Drive, St. Paul, MN. 


\section{APPENDIX}

A. Diagrams

1. DIAGRAM A - Plant Building Layout

2. DIAGRAM B - Degreaser unit

3. DIAGRAM C - Degreaser Unit shown with cleaning basket outside vapor zone 


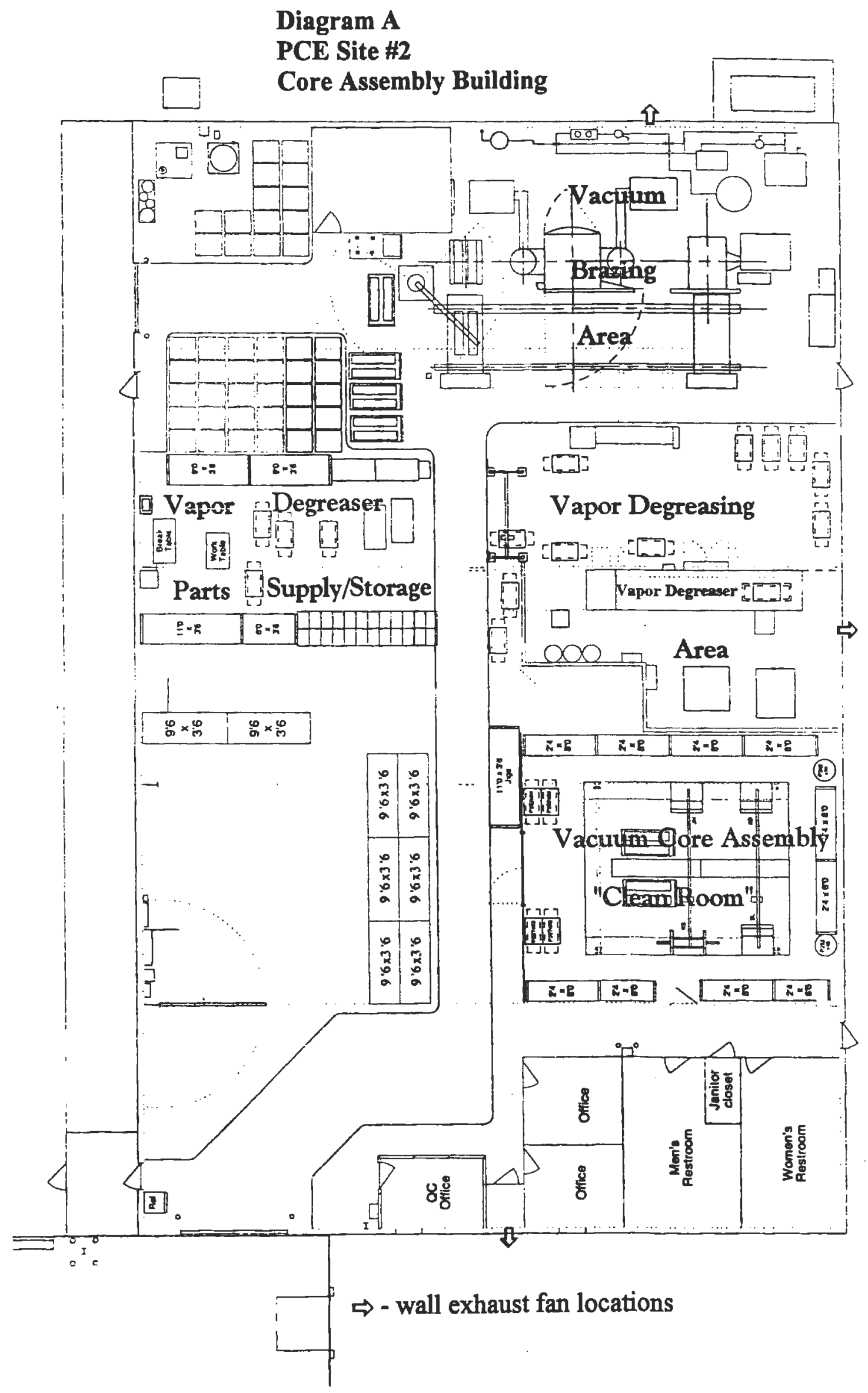



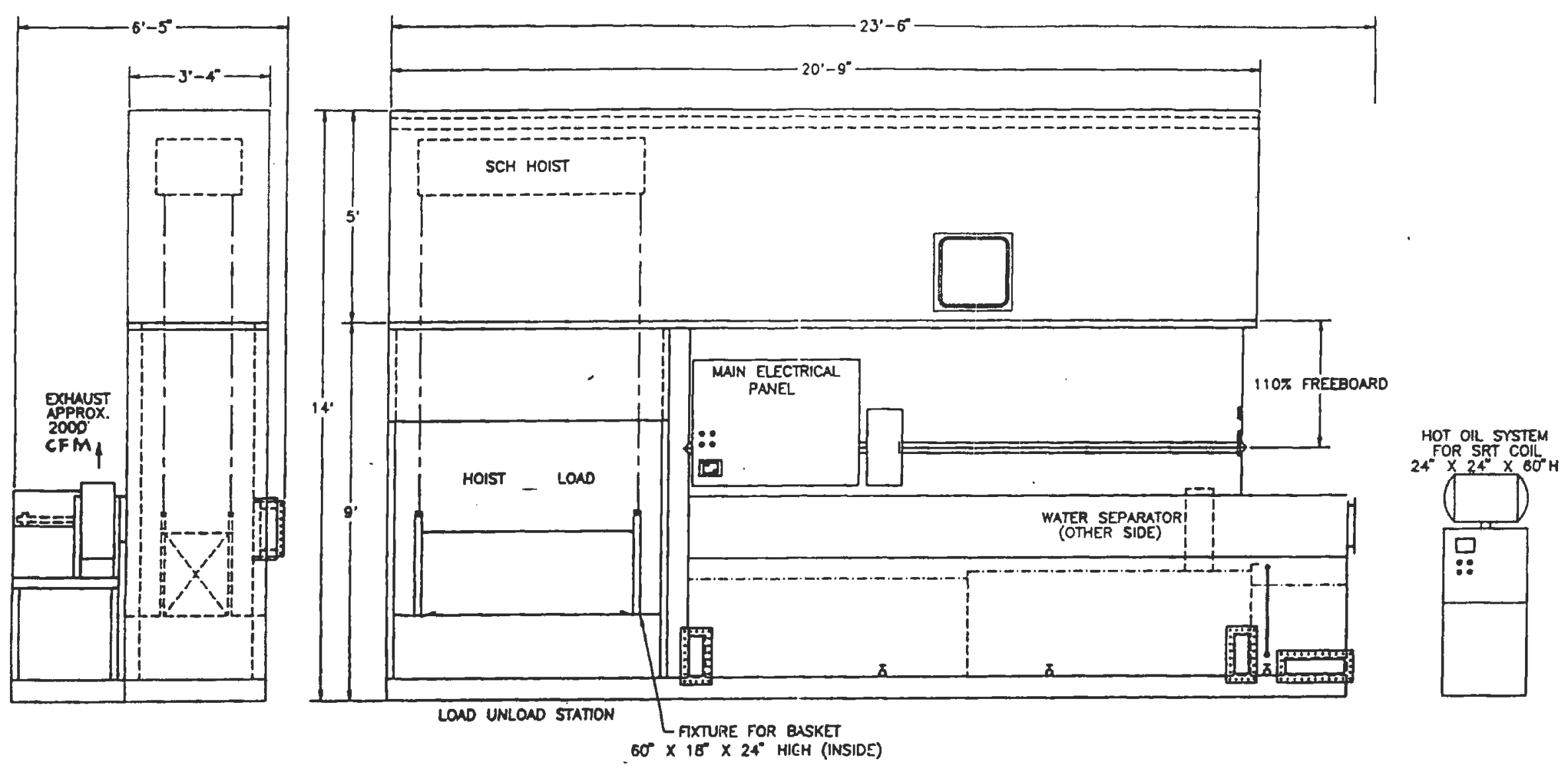

Diagram B

PCE Site \#2

Vapor Degreaser

NOTE: NL DIMENSIONS ARE APPROXIMATE 


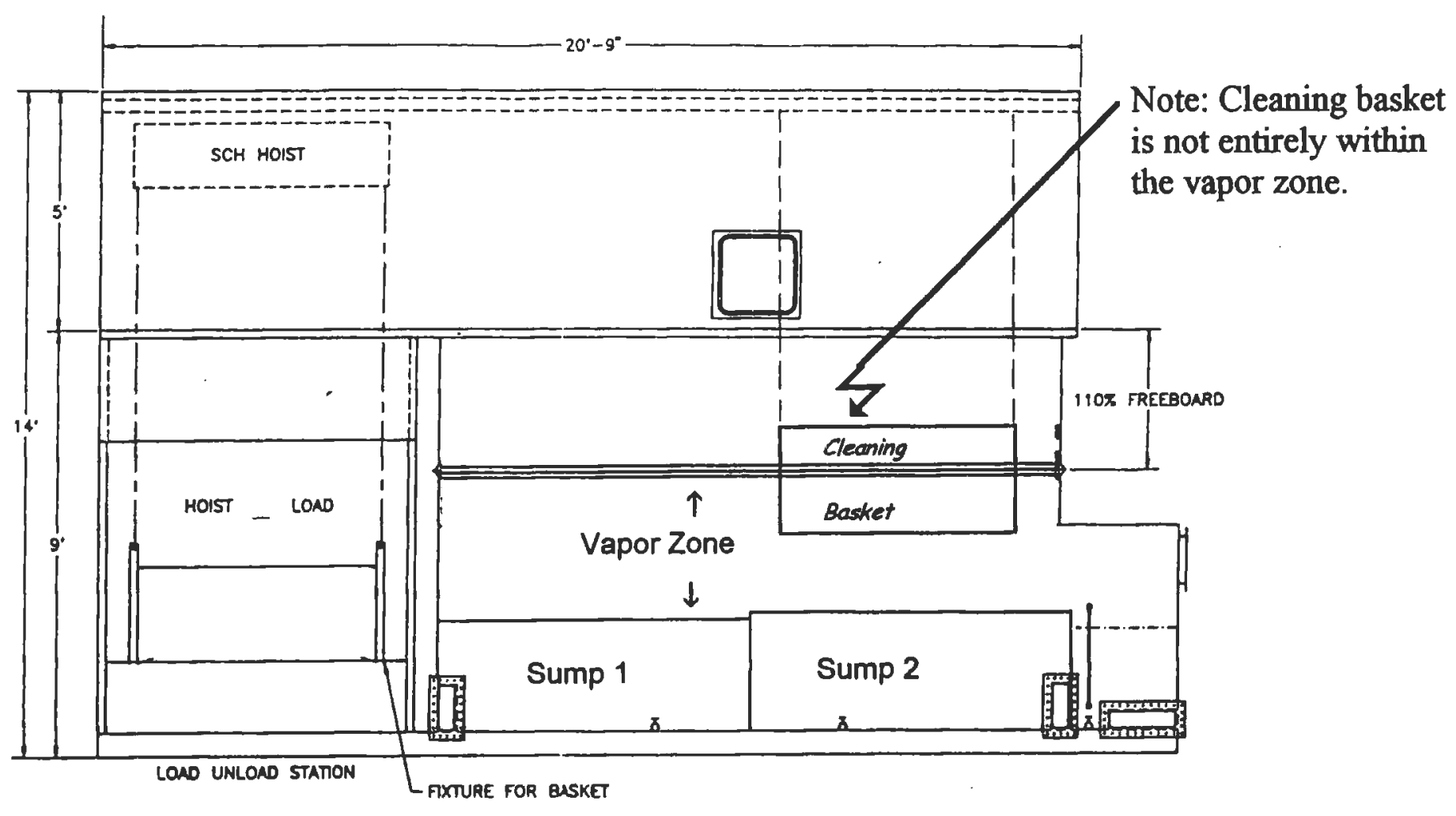

Diagram C

PCE Site \#2

Vapor Degreaser 